\title{
Special Issue on Computational Methods in Engineering (CILAMCE 2018 - Paris/Compiegne)
}

\author{
Adnan Ibrahimbegovic ${ }^{a^{*}}$ \\ Paulo M. Pimentab \\ a Universite de Technologie Compiegne - Alliance Sorbonne Universite, Laboratoire Roberval de Mecanique, Centre de Recherche \\ Royallieu, Compiegne, France. E-mail: adnan.ibrahimbegovic@utc.fr \\ b Universidade de São Paulo - Escola Politécnica, São Paulo, Brasil. E-mail: ppimenta@usp.br \\ *Corresponding author
}

http://dx.doi.org/10.1590/1679-78255739

\begin{abstract}
This special issue contains selected papers first presented in a short format at the Congress CILAMCE 2018 (39 ${ }^{\text {th }}$ Ibero-Latin American Congress on Computational Methods in Engineering) held in Paris and in Compiègne, France, from 11 to 14 November 2018.
\end{abstract}

\section{Keywords}

multiscale computations; solid mechanics; fluid mechanics.

\section{Introduction}

CILAMCE 2018 was the thirty-ninth in the series of International Congresses focusing upon Computational Methods in Engineering, held each year in Brazil. Previous meeting have all been organized under umbrella of Brazilian association ABMEC, 'Associação Brasileira de Métodos Computacionais em Engenharia', as the sponsor of CILAMCE Congress series. For this particular Congress, we had additional two sponsors from France: CSMA, Association of Computational Mechanics, and SMAI, Association of Applied and Industrial Mathematics. The institutions organizing CILAMCE 2018 were University of Technology Compiegne, a member of Sorbonne University Alliance, and Escola Politecnica of University of Sao Paulo. The CILAMCE 2018 was held from 11 to 13 November 2018 in Compiegne, with the final day of November 14 in Paris. The Congress provided a platform for learning from some of the world leading specialists in numerical methods, coming from engineering disciplines and applied mathematics.

The main idea of this CILAMCE Congress was to examine recent advances in numerical methods in currently most active research domains, with applications to interface and/or interaction of several engineering disciplines. The multiphysics models and methods of this kind are often bridging the phenomena taking place at multiple scales in space and time, which ought to be placed in interaction or accounted for simultaneously in order to provide the most reliable results explanations. This class of problems calls for the development and combination of different modeling tools and computational methods in order to advance the field towards currently relevant industrial applications. A number of different schools have developed in various domains, both in engineering sciences and mathematics, with sometimes very little or no interaction between them. It was an explicit goal of this CILAMCE Congress to bring all the different communities together, from Brazil and from France, in the truly open scientific spirit, and thus provide a sound basis for a fruitful exchange and cross-fertilization of ideas among them. The result is available in form of CILAMCE 2018 Book of Proceedings (Ibrahimbegovic, Pimenta 2018); see Figure 1. 


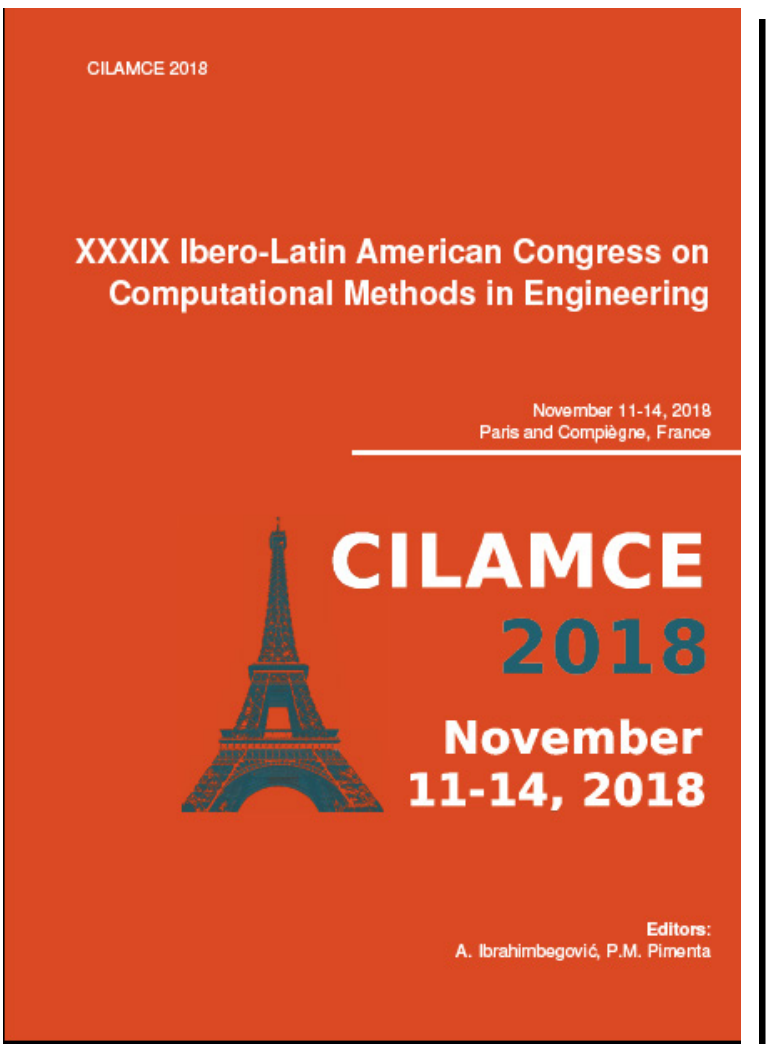

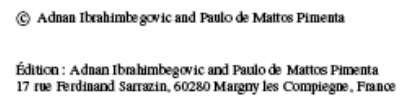

ISBN : 978-2-9565961-0-3

Depot Legal : Novembre 2018

Fig. 1 Book of Proceedings CILAMCE 2018, XXXIX in Congress Series. URL:

http://bibliotheque.utc.fr/EXPLOITATION/doc/IFD/IFD_REFDOC_0008926/cilamce-2018-proceedings-of-xxxix-ibero-latin-americancongress-on-computational-methods-in-engineer

\section{Selected papers}

The Congress topics that were addressed concerned not only 'classical' domains of Solid, Structural and Fluid Mechanics, but also a number of currently 'hot' domains, such as: Heterogeneous Materials, Complex Structures and Systems, Flow Problems, Adaptive Manufacturing, Data Mining, MEMS Devices, Industrial Applications ... The selected paper for this special issue are but a few illustration of the ideas discussed during CILAMCE 2018 Congress.

In particular, the research works of (Renan Roch Ribeiro and Rodrigo Lameiras, 2019) have studied sensing techniques based on vibration measurement for modal analysis in civil engineering structures, taking advantage of lowcost MEMS accelerometers and open-source electronic platforms.

The contribution from (Gabriel K. Rodrigues, Maira M. da Silva and Leopoldo P.R. de Oliveira, 2019) deals with modeling of smart materials that can be produced by 3D printed parts, and in particular the Fused Deposition Modeling (FDM).

In paper by (Aldemon L. Bonifácio, Julia C. Mendes, Michele C. R. Farage, Flavio S. Barbosa, Ciro B. Barbosa and Anne-Lise Beaucour, 2019), they discuss the identification problems for compressive strength and Young's modulus of concrete structures made of Lightweight Aggregate Concrete by using Support Vector Machine and Finite Element Model.

The research of (Lucas Fadini Favarato, Adenilcia Fernanda G. Calenzani, Juliana C. V. Pires, Elisabeth Junges and Johann A. Ferrareto, 2019) pertains to design of cold formed U profile as steel formwork before the concrete curing, resisting to self-weight of the concrete and contributing to the construction overload.

The contribution from (Tea Rukavina, Adnan Ibrahimbegovic and Ivica Kozar, 2019) presents a computational procedure for multi-scale analysis of reinforced concrete, where one introduces all typical failure modes, including the concrete cracks and bond-slip activation, in order to provide the estimates on crack spacing and opening of much importance for material durability.

For more details, we invite the readers to carry on with their own explorations, and I wish they be very fruitful. Last but not least, I wish to thank to all the authors of this special issue for contributing to the worthy goal of providing a more lasting impact of CILAMCE 2018 with their full-size papers. 


\section{Acknowledgments}

The research described in this paper was financially supported by the Chair for Computational Mechanics (1202015 RDISTRUCT-000010 and RDISTRUCT-000010) and EC funding (FEDER), as well as IUF funding for Member Senior.

\section{References}

Adnan Ibrahimbegovic and Paulo M. Pimenta, (2018), Proceedings CILAMCE 2018 - 39th Latin-Iberian Congress on Computational Methods in Engineering, University of Technology Compiegne, France, ISBN: 978-2-9565961-0-3; E-book: ISBN: 9782956596103.

Renan Roch Ribeiro and Rodrigo Lameiras, Evaluation of low-cost MEMS accelerometers for SHM: frequency and damping identification of civil structure, Latin American Journal of Solids and Structures, in press, (2019)

Gabriel K. Rodrigues, Maira M. da Silva and Leopoldo P.R. de Oliveira, Modular modelling approach for FDM printed structure and piezo disks for metamaterial design, Latin American Journal of Solids and Structures, in press, (2019)

Aldemon L. Bonifácio, Julia C. Mendes, Michele C. R. Farage, Flavio S. Barbosa, Ciro B. Barbosa and Anne-Lise Beaucour, Application of Support Vector Machine and Finite Element Method to predict the mechanical properties of concrete, Latin American Journal of Solids and Structures, in press, (2019)

Lucas Fadini Favarato, Adenilcia Fernanda G. Calenzani, Juliana C. V. Pires, Elisabeth Junges and Johann A. Ferrareto, Evaluation of the resistance of trussed slabs with steel formwork in cold formed U profile, Latin American Journal of Solids and Structures, in press, (2019)

Tea Rukavina, Adnan Ibrahimbegovic, Ivica Kozar, Multi-scale representation of plastic deformation in fiber-reinforced materials: application to reinforced concrete, Latin American Journal of Solids and Structures, in press, (2019) 